\title{
Representation of health as a subject of psychological researches
}

\author{
Filipp Filatov* \\ Don State Technical University, Faculty "Psychology, Pedagogy and Defectology", \\ 344000 Rostov-on-Don, Russian Federation
}

\begin{abstract}
In this article the author describes a long-term comprehensive study of various forms of social and individual health representation in a youth (student) social group. A theoretical analysis of various approaches to understanding the phenomenon of health, developed in the framework of social medicine, clinical psychology, a psychosomatic school, behavioral and cognitive areas of psychology and psychotherapy, humanistic personality theories, is carried out. Different levels of conceptualization of the health phenomenon are considered (as a socio-cultural / semantic construct and as a significant aspect of an individual self-concept). The author analyzes the theoretical foundations and scientific specifics of the Health psychology, as an independent field of psychological knowledge. The author also analyzes the results of a comprehensive study of the "internal representation of health" that was formed among junior students of natural sciences and humanities departments at the Russian State University. Specific types of the internal representation of health are revealed and described.
\end{abstract}

\section{Introduction}

Researches on the social and individual representation of health are the priority area of modern health psychology. The health psychology, as an independent scientific and practical direction, was formed in the USA in the 1970s. [1, 2, 3, 4, 5]. During this period, a social request for psychological support of medical practice and a comprehensive study of the psychogenic factors of various somatic diseases was conceptually framed [6]. The theoretical basis of the health psychology includes social medicine, clinical psychology, behavioral sciences, a psychosomatic school, as well as socio-psychological and humanistic theories of personality $[7,8,9]$.

The psychological factors of various diseases, as well as the processes of recovery and treatment, have been studied before, in the context of stress studying, investigations of psychogenic and iatrogenic dysfunctions, the internal representation of disease, etc. So, the representatives of the psychosomatic school formulated the task of revealing the psychological mechanisms of the personality influence on the disease, its occurrence,

\footnotetext{
${ }^{*}$ Corresponding author: filatov filipp@,mail.ru
} 
development, overcoming or anticipation. Psychologists of the behavioral school focused on the behavioral prerequisites of various disorders of the body and psyche healthy functioning. The anticipation of the psychological concept of health was in the work of humanistic psychologists: G. Allport, A. Maslow, C. Rogers. In particular, A. Maslow, in the fundamental monograph "Towards a Psychology of Being", called on colleagues to create jointly, along with a sufficiently developed and differentiated psychopathology, the psychology of a healthy person [10]. He sought to implement this project in the framework of the concept of self-actualization and self-actualizing personality, formulating the principles of a healthy existence based on the psychobiographies of prominent people who were able to successfully realize their creative and spiritual potential in various fields of activity and public life [10].

All of the above contributed to the formation of the so-called biopsychosocial model, which served as the theoretical core of the psychological science of health. According to this model, health was seen as a complex, multicomponent phenomenon, an integrated product of heredity, social and sociocultural living conditions and behavioral patterns of an individual. Further studies of the health phenomenon became interdisciplinary, the specific gravity of their humanitarian component increased (along with a biopsychological, medical approach). In such systemic perspective health was considered in its integrity and universality, as a complexly constructed and diverse determinant of the development of human, society, humanity as a whole. Significant conceptual shifts have occurred in understanding health. Firstly, there had been a transition from fixing normative, i.e. general health parameters for a certain population (which was characteristic of a normocentric approach rooted in medicine) to description of health as a basic integrative characteristic of a person. Secondly, the initial focus on the phenomena of psychopathology (the so-called pathocentric approach) had given way to the study of the basics mechanisms and factors of "healthy person's health" $[11,12]$.

Summarizing the various areas of researches, we can distinguish a number of descriptive models in which health is defined as: 1) the essential property (attribute) of human nature; 2) an integrative personality trait, consisting of a number of biological, psychological, social and spiritual indicators; 3 ) one of the basic values of culture and value orientations of the individual; 4) the quality of human life, i.e. characteristic of an individual's life path as a complex multi-stage process of self-realization, and, simultaneously, as a characteristic of society. Within the framework of psychological research, the health phenomenon can also be represented at different levels of conceptualization: 1) as a conceptual (semantic) construct formed in certain socio-cultural conditions and a social representation which characterizes different social groups or communities; 2) as a significant aspect of the individual self-conception [13]. A special area of researches is the representation of health in self-awareness and the value system of the individual.

The main form of health reflection in the personality structure and in the sphere of selfconsciousness is the "internal representation of health". The term "internal representation of health" was introduced into psychological theory by analogy with earlier and wellestablished clinical concepts "autoplastic representation of the disease" and "internal representation of the disease" (A.R. Luria, 1945) [14]. The internal representation is an integral characteristic of the subject and the specific components of the self-concept, as well as self-esteem and various parameters of the value-semantic sphere. We consider the internal representation of health in a cognitive sense as a system of formed subject's (in our study, student's) ideas about the essence of health in general, as well as about the possibilities and necessary conditions of his own health, in particular. 


\section{Sample}

The empirical object of our study was junior students of natural science and humanities faculties (total 470 people). Empirical studies have been conducted for 8 years (2008 2016).

The representativeness of the sample was ensured by random selection of the participants, without taking into account gender-role, status, other demographic and psychosocial characteristics. At the same time the health of the participants was taken into account. An important criterion for the selection of participants in an empirical study was the absence of any chronic diseases that could have a significant effect on the internal representation of health, which is not recognizable by the methods we have chosen. The primary professional orientation of students was taken into account: for natural science or humanitarian disciplines, their belonging to a particular faculty was recorded. This is explained by the fact that occupational orientations, like the internal representation of health, according to our approach, are stable $\neg$ components of the student's "Selfconception" and can be significantly related to his ideas about health and health lifestyle. The size of the sample was determined by the possibility of viewing it in those cases when manual data processing was used, as well as by the restrictions imposed on the initial information by the statistical methods used by us. The age of the participants is in the range from 18 years to 21 years.

\section{Methods}

In the process of researches we used the following methods.

1. The diagnostic test methodology implemented in the following methods (in particular, projective):

1.1. The method of indirect measurement of the self-esteem system, developed by E.T.

Sokolova and E.O. Fedorova (1981).

1.2. Lüscher color test.

1.3. Gissensky questionnaire, adapted at Vladimir Bekhterev's Psychoneurological Institute.

1.4. The scale of subjective well-being;

1.5. "Motivation for success and fear of failure" (A.A. Reznova);

1.6. "Diagnosis of a person's predisposition to conflict behavior" by K. Thomas (as adapted by N.V. Grishina, 1973);

1.7. The Wiesbaden Questionnaire (WIPPF), which allows revealing not only the usual forms of social interaction (such as the Thomas questionnaire), but also the most general, global strategies related to deep relations with oneself and the world;

1.8. Methodology for diagnosing attitude to oneself of V.V. Stolin;

1.9. Methodology "Cognitive orientation" (locus of control);

1.10. A technique for diagnosing the level of social frustration of L.I. Wasserman (as modified by V.V. Boyko).

2. The psychosemantic method.

3. Additional empirical method: thematic analysis of texts.

4. Data Processing Methods:

4.1. Quantitative (statistical) methods. For mathematical data processing, the computerbased statistical analysis program STATISTICA was used.

4.2. Qualitative methods (differentiation of material into groups and categories, description of typical cases, etc.). 


\section{Results}

In general, by means of our empirical studies we obtained the following results.

1. A significant and reliable relationship has been revealed between the individual internal representation of the student's health with such variables as:

1) subjective assessment of psycho-emotional well-being;

2) the level of psychosocial adaptation;

3) level of satisfaction with self-realization.

Thus, the concept of health and the assessment of the conditions, resources and capabilities of one's own health are significantly related to self-esteem in terms of such parameters as internal coherence, social adaptation and self-realization.

2. The grading of varieties of the internal representation of health was carried out in accordance with the level of differentiation of health representations. The following levels of health representation in the person's self-awareness system were identified:

1) An integrative, holistic view that combines the totality of biological, psychosocial and spiritual aspects of health;

2) Selective representation of health, in which one of its components is emphasized and dominates;

3) Diffuse, undifferentiated representation;

4) Representation based on negation: health is defined as the absence of disease and lacks independent cognitive content.

3. It has been established that the ideas about health and a healthy lifestyle, which are part of the internal representation of health, significantly differ depending on the state of health in the individual value system.

4. It has been revealed that health is characterized by a dual representation in the value system, that is, health as a basic value can be represented within the framework of an individual internal representation of health, either as a "health-goal" ("to be healthy"), or as a mean of achieving other goals and realizing other values (prestige, social success, creative productivity, etc.).

5. Eight relatively independent types of the internal representation of health were distinguished, significantly differing in cognitive and value-semantic parameters. The basis of these typological differences are: 1) emphasis in the framework of the internal representation of health of one of the four components of health - physical, psychological, social or spiritual; 2) the dominance in the composition of the internal representation of health of one of two types of interpretation of health: as a condition of well-being and as a necessary condition for self-realization. Accordingly, the types of interpretations that we highlighted suggest an interpretation of the health phenomenon (its representation in the personality self-awareness system) as:

1) a condition of complete physical well-being;

2) the conditions for the maximum realization of the physical capabilities of a person;

3) conditions for the maximum realization of the physical claims of the individual;

4) a condition of complete social well-being;

5) conditions for maximizing the realization of human social capabilities;

6) the conditions for the maximum realization of the social claims of the individual;

7) a condition of complete mental well-being;

8) the conditions for the maximum realization of a person's spiritual capabilities.

6. Ideas about a healthy lifestyle vary (significantly differ) depending on the nature of the representation of health in the person's self-awareness system and on the type of interpretation of this phenomenon. 
7. Depending on the type of interpretation of health, a healthy lifestyle can be represented within the internal representation of health as: 1) a system of restrictions and prohibitions ("interdictory" type of interpretation); 2) a way to achieve physical attractiveness; 3) performance indicator; 4) following certain norms and standards; 5) an element of social prestige; 6) an indicator of the quality of life (material and social wellbeing); 7) a consciously chosen lifestyle; 8) a component of ideology, philosophy of life, spiritual practice.

\section{Conclusion}

On the base of obtained empirical data we can make an assumption that requires additional verification: the internal representation of health, in an ensemble with other characteristics of self-awareness (self-esteem, self-attitude) and the value-semantic sphere of the personality, is one of the factors in regulating individual behavior and human activity in the field of maintaining, strengthening and use of own health resources. This makes it possible both a probabilistic forecast and the development of specialized correctional programs designed to optimize and differentiate a person's representation of health and attitude to his own health.

\section{References}

1. A. Baum, T.A. Revenson, J.E. Singer, Handbook of Health Psychology (Psychology Press, New York, 2012)

2. L. Brannon, J.A. Updegraff, J. Feist, Health Psychology: An Introduction to Behavior and Health (Cengage Learning, Boston, 2014)

3. I. Lubek, M. Murray, Journal of Health Psych. 23(3), 361-523 (2018)

4. D. Marks, M. Murray, B. Evans, C. Willing, Health psychology: Theory, Research and Practice (Sage, London, 2010)

5. M. Murray, Journal of Health psych., 5(3), $132-145$ (2000)

6. M. Murray, Psychology Review. 8, 215-237 (2014)

7. M. Murray, Journal of Health Psych. 23(3), 472-491, (2018)

8. M. Murray, K. Chamberlain, Journal of Health psych., 3 (3), 99 - 116 (1998)

9. E. Freedland, Health Psych., 36 (1), 1-4 (2017)

10. A. Maslow, Toward a psychology of being (Princeton, New Jersey, 1962)

11.F.R. Filatov, O.S. Vasil'eva, Psihologiya zdorov'ya cheloveka. Etalony, predstavleniya, ustanovki. (Akademiya, Moscow, 2001)

12. F.R. Filatov, O.S. Vasil'eva, Psihologiya zdorov'ya. Fenomen zdorov'ya v kul'ture, psihologicheskoj nauke i obydennom soznanii (Mini Tajp, Rostov-on-Don, 2005)

13. F.R. Filatov, O.S. Vasil'eva, Psihologiya i kul'tura zdorov'ya: Bazovye ponyatiya, koncepcii i podhody (South Federal University, Rostov-on-Don, 2011)

14. A.R. Luria, Vnutrennaya kartina bolezni $i$ yatrogennyye (USSR Academy of Medical Sciences Publishing House, Moscow, 1945) 